\title{
SAÚDE: Direito Assegurado Constitucionalmente ${ }^{1}$
}

\author{
Fabiane Barchet ${ }^{2}$ \\ João Érico Lucas Coelho ${ }^{3}$
}

\begin{abstract}
RESUMO: A Constituição Federal almeja a igualdade entre os seres humanos, tratamento igualitário independente de sua origem. Logo, surge o ordenamento social que busca o bem-estar e a justiça social, seus aspectos são regidos com o objetivo de trazer igualdade de condições e condições adequadas às necessidades básicas do ser humano. Concentra-se o referido trabalho na ordem social referente à saúde, um acesso devido a todos e que apresenta um trâmite que, muitas vezes, pode ocasionar sérios danos, devido à lenta marcha da máquina jurisdicional. Assim, tentando-se amenizar sofrimentos maiores, responsabiliza-se o Poder Público vindo desta forma a gerar uma grande discussão de quem seria responsabilidade no fornecimento dos referidos medicamentos.
\end{abstract}

PALAVRAS-CHAVE: Saúde, Constituição Federal, Poder Público

\section{HEALTH: Assured Constitutionally Right}

\begin{abstract}
The Constitution aims at the equality among human beings, equal treatment regardless of their origin. Therefore, there is the social order that seeks the welfare and social justice aspects are regulated in order to bring equal terms and conditions appropriate to the basic needs of human beings. Focuses on the study cited in the social order related to health, access and because of all that presents a channel which often causes serious damages due to the slow pace of judicial machinery. Thus, trying to ease suffering larger responsibility to the Government coming this way to generate a large discussion of who would be responsible in the supply of such medicines.
\end{abstract}

KEY-WORDS: Health, Constitution, Government

\section{INTRODUÇÃO}

A Constituição Federal, em seu sentido lato sensu, apresenta-se como um ato de constituir, estabelecer e firmar, ou seja, é o modo pelo qual se constitui uma coisa, desde sua organização até sua formação. Deste modo, a Carta Magna é jurisdicionalmente reconhecida como sendo a lei/norma fundamental e suprema de um Estado, de uma sociedade, que contém a forma pela qual deve ser regida, estabelecendo sua estruturação, formação dos poderes públicos, forma de governo e poder para governar, distribuição de competências, direitos, garantias e deveres dos cidadãos.

Em regra, é qualificada como norma fundamental aquela que em certa comunidade política unifica e confere validade às suas normas jurídicas, e a partir dela se organiza e

\footnotetext{
${ }^{1}$ Trata das questões relacionadas à saúde que se encontram e m debates judiciais.

${ }^{2}$ Acadêmica do VII semestre do Curso de Direito da URI, campus Santiago-RS. Email fabi.fbi@ hotmail.com

${ }^{3}$ Orientador e professor do Curso de Direito da URI, campus Santiago-RS
} 
estrutura um sistema; em outras palavras, "é a que constitui a unidade de uma pluralidade de normas, enquanto representa o fundamento de validade de todas as normas pertencentes a essa ordem normativa; aquela norma que, pelo fato mesmo de situar-se na base do ordenamento jurídico, há de ser pressuposta, visto que não pode ser posta por nenhuma autoridade, a qual se existisse e tivesse competência para editá-la, só disporia dessa prerrogativa em razão de uma outra norma de hierarquia ainda mais elevada, $e$ assim sucessivamente; aquela norma, enfim, cuja validade não pode ser derivada de outra e cujo fundamento não pode ser posto em questão." 4

Ressalta-se o conceito ideal de constituição que veio a vigorar com o triunfo do movimento constitucional no início do século XIX, o qual cita CANOTILHO:

Este conceito ideal identifica-se fundamentalmente com os postulados políticoliberais, considerando-os como elementos materiais caracterizadores e distintivos os seguintes: (a) a constituição deve consagrar um sistema de garantias da liberdade (esta essencialmente concebida no sentido do reconhecimento de direitos individuais e da participação dos cidadãos nos atos do poder legislativo através do parlamento) $[\ldots]^{5}$

A Constituição possui como principal classificação, seu aspecto analítico, o qual, desta forma, examina e regulamenta todos os assuntos relevantes à formação, destinação e funcionamento do Estado, além de também ser posta como formal, escrita, legal, dogmática, promulgada (democrática e popular) e rígida.

As garantias institucionais vêm viabilizar aos cidadãos seu direito de exigir dos Poderes Públicos a proteção do que lhe é garantido por lei, a realizar-se com o reconhecimento de meios processuais adequados a essa finalidade, por exemplo, a saúde se apresenta como um direito de todos e um dever do Estado, logo, os direitos declaram-se, as garantias estabelecem-se. Em seu artigo $5^{\circ}$, a Constituição afirma que todos são iguais perante a lei, sem distinção de qualquer natureza, vindo desta forma a se compreender que todos possuem direitos iguais independente de suas etnias, sem se fazer distinções e restrições ao acesso a tais direitos. Da mesma forma, seguindo o referido artigo, este

\footnotetext{
${ }^{4}$ Mendes, Gilmar Ferreira; Coelho, Inocêncio Mártires; Branco, Paulo Gustavo Gonet. Curso de Direito Constitucional. $3^{\circ}$ Ed. São Paulo: Saraiva, 2008. p. 1 e 2

${ }^{5}$ Moraes, Alexandre de. Direito Constitucional. $15^{\circ}$ Ed. São Paulo: Atlas, 2004. p.38
} 
promulga a inviolabilidade do direito à vida, sendo o mais fundamental de todos os direitos, visto ser um pré-requisito à existência e exercício dos demais diretos.

Proclamado, portanto, o direito à vida, cabe ao Estado exercer sua função a fim de assegurar essa dupla acepção, a qual se relaciona ao direito de continuar vivo e de ter vida digna quanto à subsistência. A vida, do ponto de vista biológico, se inicia com a fecundação do óvulo pelo espermatozóide, sendo desta forma garantidos, desde já, ao nascituro, seus direitos a partir da fecundação (início da gravidez), visto que a Constituição protege a vida de uma forma geral, inclusive uterina.

Garantido o direito à vida, e sendo esta concebida, ainda que no útero materno, rege-se consequentemente o princípio da igualdade de direitos, onde todos os cidadãos possuem o direito de tratamento idêntico pela lei, em consonância com os critérios albergados pelo ordenamento jurídico, assim, são vedadas diferenciações arbitrárias, pois o que realmente se protege é certa finalidade. Desta forma, a igualdade consagrada pela Constituição opera frente ao legislador e ao Poder Executivo, impedindo que se criem tratamentos diferenciados a pessoas que se encontram em situações idênticas, e também opera frente à autoridade pública, a fim de que aplique a norma de forma igualitária, sem estabelecer distinções em razão de sexo, raça, classe social e outros aspectos.

Compreende-se, então, que normas que criem diferenciações abusivas e arbitrárias, sem qualquer finalidade lícita, serão tidas como incompatíveis com a Constituição, da mesma forma que, não poderá se aplicar normas a casos concretos que possam criar ou aumentar desigualdades arbitrárias.

Consequentemente, estabelecida a igualdade entre as pessoas, a Constituição vem a referir seus direitos sociais que, dentre outros, destaca o direito à saúde (Constituição Federal, artigo $6^{6^{6}}$ ), onde o ser humano se apresenta como seu destinatário, que também decorre da previsão do artigo 196 da Constituição ${ }^{7}$, em cotejo com o artigo $1^{\circ}$, III, da mesma $\operatorname{Carta}^{8}$. Esses direitos surgem das perspectivas de um Estado Social de Direito, que

\footnotetext{
6 “Art.6": São direitos sociais a educação, a saúde, o trabalho, a moradia, o lazer, a segurança, a previdência social, a proteção à maternidade e à infância, a assistência aos desamparados, na forma desta Constituição.”

7 “Art.196: A saúde é direito de todos e dever do Estado, garantido mediante políticas sociais e econômicas que visem à redução do risco de doença e de outros agravos e ao acesso universal e igualitário às ações e serviços para sua promoção, proteção e recuperação."

8 “Art.1\%: A República Federativa do Brasil, formada pela união indissolúvel dos Estados e Municípios e do Distrito Federal, constitui-se em Estado Democrático de Direito e tem como fundamentos: III - a dignidade da pessoa humana.”
} 
vem a ser elaborado em consonância com o descrito na Constituição Mexicana de 1917, na de Weimar, na Alemanha, em 1919, e no Brasil, em 1934, e que tende a concretizar a perspectiva de uma isonomia substancial e social na busca de melhores e adequadas condições de vida. Ao contrário do entendimento de muitas pessoas, os direitos sociais possuem aplicação imediata (artigo $5^{\circ}$, Constituição Federal brasileira), podendo ser implementados no caso de omissão legislativa, pelas formas de controle, como o mandado de injunção ou a ação direta de inconstitucionalidade por omissão (ADO). Da previsão do direito prestacional à saúde, associado ao Princípio da Dignidade da Pessoa Humana, infere-se que o direito é devido ao requerente pela simples e verdadeira razão de ser, o direito à vida, o requisito racional de todo o sistema constitucional, baseado na Dignidade da Pessoa Humana, pilar maior do ordenamento jurídico brasileiro.

\section{A SAÚDE NO ORDENAMENTO SOCIAL}

A ordem social possui como objetivo o bem-estar e a justiça social, posteriormente, a Constituição Federal vem abranger a seguridade social e esta, normas referentes à saúde, reconhecidamente tida como um direito de todos e dever do Estado e regida pelos princípios da universalidade, da igualdade, da unidade de organização pelo Poder Público e pela solidariedade financeira, visto abranger um conjunto de ações de iniciativa dos Poderes Públicos e da sociedade.

A saúde, sendo um direito assegurado frente à seguridade social, através de ações de iniciativa dos Poderes Públicos e da sociedade, vem a ser financiada por esta, de forma direta e indireta, através de recursos provenientes dos orçamentos da União, dos Estados, do Distrito Federal, dos Municípios e de contribuições sociais, e em nenhum momento a questão dos recursos pode vir a acarretar transtornos e atrasos relacionados a questões da saúde, conforme nota-se na decisão da quarta Câmara Cível do Tribunal de Justiça do Rio Grande do Sul

Eventuais limitações ou dificuldades orçamentárias não podem servir de pretexto para negar o direito à saúde e à vida, garantidos no dispositivo constitucional, não 
havendo que se cogitar, desse modo, da incidência do princípio da reserva do possível, dada a prevalência do direito em questão. ${ }^{9}$

Desta forma, compete ao Poder Público a organização da seguridade, em especial garantindo universalidade da cobertura e do atendimento a questões referentes à saúde, porém, frente ao agravamento das desigualdades sociais e da limitação de recursos, esta garantia vem se tornando cada vez mais tensa nas relações entre a sociedade e os Poderes do Estado. Nota-se com o Judiciário a cobrança de decisões que esbarram em suas competências, sendo que, frequentemente, impõem às autoridades administrativas a satisfação de necessidades individuais, decorrentes de situações que se tornam aflitivas, como internações hospitalares, independentemente da disponibilidade de leitos, ou o "simples" fornecimento de remédios, na maioria das vezes inexistentes ou de altíssimo custo e dependentes de importação, sem que haja recursos legalmente destinados a custear as despesas que decorrem destas determinações.

Nesse contexto, declara-se ser a saúde um direito de todos e dever do Estado, garantido mediante políticas sociais e econômicas que visem à redução do risco de doenças e de outros agravos e ao acesso universal e igualitário às ações e serviços para sua promoção, proteção e recuperação (artigo 196 da Constituição Federal), sendo de relevância pública as ações e serviços de saúde, cabendo ao Poder Público dispor, nos termos da lei, sobre sua regulamentação, fiscalização e controle, devendo sua execução ser feita diretamente ou por meio de terceiros e, também, por pessoa física ou jurídica de direito privado (artigo 197 da Constituição Federal ${ }^{10}$ ). Assim, a saúde constitui um direito público subjetivo, que pode ser exigido do Estado, ao qual é imposto o dever de prestá-lo.

Nesse ponto de vista, a doutrina apresenta uma dupla vertente dos direitos sociais no que se refere à saúde, sendo: a) natureza negativa: Estado ou terceiros devem se abster de praticar atos que prejudiquem terceiros; b) natureza positiva: estimula-se um Estado prestacionista para implementar os direitos sociais.

O artigo 198 da Constituição Federal declara que as ações e serviços públicos de saúde integram uma rede regionalizada e hierarquizada e constituem um sistema único de

\footnotetext{
9 Apelação Cível No 70035483619, Quarta Câmara Cível, Tribunal de Justiça do RS, Relator: Ricardo Moreira Lins Pastl, Julgado em 28/04/2010

10 “Art.197: São de relevância pública as ações e serviços de saúde, cabendo ao Poder Público dispor, nos termos da lei, sobre sua regulamentação, fiscalização e controle, devendo sua execução ser feita diretamente ou através de terceiros e, também, por pessoa física ou jurídica de direito privado.”
} 
saúde, sendo organizado pela descentralização, com direção única em cada esfera de governo, que proporcionam atendimento integral, priorizando as atividades preventivas, sem prejuízo de serviços assistenciais e participação da comunidade. O Sistema Único de Saúde vem a ser financiado com recursos do orçamento da seguridade social da União, Estados, Distrito Federal, Municípios e contribuições sociais, e em casos especiais possibilita que instituições privadas façam parte, vindo a integrar, mediante contrato de direito público ou convênio, tendo preferência a entidades filantrópicas e as sem fins lucrativos. Sendo a saúde financiada pelo Poder Público, é vedada, salvo casos declarados em lei, a participação direta ou indireta de empresas ou capitais estrangeiros em sua assistência, bem como é vedada, a destinação de recursos públicos para auxílio ou subvenções às instituições privadas com fins lucrativos.

As funções do Sistema Único de Saúde estão expressas no artigo 200 da Constituição Federal, dentre elas está ordenar a formação de recursos humanos na área de saúde e controlar e fiscalizar procedimentos, produtos e substâncias de interesse para a saúde, além de participar da produção de medicamentos, equipamentos imunológicos, hemoderivados e outros insumos. Posteriormente, não sendo cumpridos os direitos referentes à saúde, começa o procedimento da previdência social, também abrangida pela seguridade social, que possui entre suas funções a cobertura dos eventos provenientes de doenças.

Além da Carta Magna, a questão da saúde também se encontra expressa em leis esparsas, o Estatuto do Idoso, Lei n ${ }^{o}$ 10.741/03, apresenta o Princípio da Solidariedade, obrigando a família, a comunidade, a sociedade em geral e o Poder Público a assegurarem, com absoluta prioridade, o direito à saúde, dentre outros. Sendo o envelhecimento um fator natural, tido como um direito personalíssimo, é obrigação do Estado garantir ao idoso a proteção a sua vida e saúde já debilitada, através de políticas sociais públicas que permitem um envelhecimento saudável e em condições de dignidade.

Corroborando ao expresso na Constituição, o Estatuto do Idoso ressalta, em seu Capítulo IV - Do Direito à Saúde, que é assegurada atenção integral à saúde do idoso, através do Sistema Único de Saúde, preservando acesso universal, igualitário e contínuo das ações e serviços, a fỉm de proporcionar a prevenção, proteção e recuperação da saúde, concedendo atenção especial às doenças que afetam preferencialmente aos idosos. A 
proteção à saúde do idoso será essencialmente através de atendimentos geriátricos e gerontológicos, atendendo a todos os necessitados, inclusive os impossibilitados de se locomoverem, os abrigados e acolhidos por instituições.

Ressaltando-se, mais uma vez, ser a saúde um direito de todos e dever do Estado, cita-se o artigo $2^{\circ}$ do Estatuto do Idoso, onde fortalece o expresso na Constituição Federal, tornando-se ainda mais efetiva a incidência do Princípio da Dignidade da Pessoa Humana, ao cumulá-lo com o Princípio da Prioridade Absoluta

O idoso goza de todos os direitos fundamentais inerentes à pessoa humana, sem prejuízo da proteção integral de que trata esta Lei, assegurando-se-lhe, por lei ou por outros meios, todas as oportunidades e facilidades, para preservação de sua saúde física e mental [...]

Seguindo o mesmo raciocínio, o Estatuto da Criança e do Adolescente, Lei $\mathrm{n}^{\circ}$ $8.069 / 90$, assegura

Art. $7^{o}$ - A criança e o Adolescente têm direito a proteção, à vida e à saúde, mediante a efetivação de políticas sociais públicas que permitam o nascimento e o desenvolvimento sadio e harmonioso, em condições dignas de existência.

Por fim, o artigo $1^{\circ}$ da Lei Estadual $n^{\circ}$ 9.908/93 garante o direito de receber gratuitamente remédios excepcionais, dispondo que:

O Estado deve fornecer, de forma gratuita, medicamentos excepcionais para pessoas que não podem prover as despesas com os referidos medicamentos, sem privarem-se dos recursos indispensáveis ao próprio sustento e de sua família.

Parágrafo único - Consideram-se medicamentos excepcionais aqueles que devem ser usados com frequência e de forma permanente, sendo indispensável à vida do paciente.

Desta forma, observa-se ser um direito amplamente assegurado, tanto em sua assistência técnica, quanto nos métodos de sua aplicação.

\subsection{A responsabilidade quanto o fornecimento}


Frente à impossibilidade de se adquirir os medicamentos necessários ao resguardo da saúde, e de viés, à vida, e não estando estes disponíveis junto aos órgãos destinados ao seu fornecimento, começa-se um demorado trâmite processual junto a órgãos públicos, por se tratar de pessoas necessitadas que não dispõem de fundos para arcar com honorários advocatícios. Efetivado o processo, inicia-se a discussão entre os entes públicos, onde alegam ilegitimidade passiva frente a ações que almejam o fornecimento gratuito de medicamentos, principalmente quando os medicamentos pleiteados não fazem parte da lista dos medicamentos essenciais constantes da Portaria n $2.475 / 2006$, do Ministério da Saúde (RENAME), na hipótese dos Municípios, ou medicamentos excepcionais e especiais, constantes respectivamente na Portaria n ${ }^{\circ}$ 2.577/06, do Ministério da Saúde, e Portaria $n^{\circ}$ 238, de 2006, da Secretaria Estadual da Saúde, quando se referem ao Estado do Rio Grande do Sul.

Porém, embora estabelecida as referidas listas, a Lei Maior de nosso país assegura ser a saúde um direito de todos, indo desta forma além do estabelecido nas referidas listas das portarias, não se questionando, desta forma, a quem cabe especificamente o fornecimento/arcar com os custos da referida medicação, mas sim, se estabelecendo uma responsabilidade solidária entre os referidos órgãos. Nesse sentido, consagrou o Tribunal

[...]1. Ilegitimidade Passiva ad causam. A União, Estado e Município são solidariamente responsáveis pela prestação do direito à vida, que é obrigação do Estado, em abstrato, desimportando qual a esfera de poder estatal que a realiza. Não-acolhimento. 2. Mérito. É consabido que a Saúde Pública é obrigação do Estado em abstrato, desimportando qual a esfera de poder que, efetivamente, a cumpre, pois a sociedade que contribui e tudo paga, indistintamente, ao ente público que lhe exige tributos cada vez mais crescentes, em todas e quaisquer esferas de poder estatal, sem que a cada qual seja especificada a destinação desses recursos. Nesse contexto, o direito à vida e o direito à saúde são direitos subjetivos inalienáveis, constitucionalmente consagrados, cujo "primado supera restrições legais. [...] (Apelação Cível $n^{o}$ 70022310502, $4^{a}$ Câmara Cível do TJRS, Rel. Wellington Pacheco Barros. j. 30.01.2008, DJ 14.02.2008)

Confirmando, reza o parágrafo $2^{\circ}$ do artigo 15, do Estatuto do Idoso, o qual declara "Incumbe ao Poder Público fornecer aos idosos, gratuitamente, medicamentos, especialmente os de uso continuado, assim como próteses, órteses e outros recursos relativos ao tratamento, habilitação ou reabilitação". 
Desta forma, a negativa do direito à medicação postulada, acaso não suprida pelos entes públicos, demonstra um conjunto de ações executivas em franca contrariedade à Constituição, seja pela desobediência ao seu artigo 196, seja por ferir a Constituição Federal como um todo, maculando sua essência, qual seja, a dignidade da pessoa humana.

\section{CONSIDERAÇÕES FINAIS}

A Constituição Federal assegura claramente ser a saúde um direito de todos e um dever do Estado, bem como, diversas leis complementares trazem a mesma base legal, onde incumbe ao Poder Público o fornecimento de medicamentos e demais recursos adequados para se assegurar condições dignas de saúde. Para tal acesso, não há uma escolha quanto à classe ou etnia, visto que a Carta Magna considera o ser humano um só, sem distinções, momento em que ressalta em seus direitos e garantias fundamentais que "todos são iguais perante a lei, sem distinção de qualquer natureza" (artigo $5^{\circ}$, caput, da Constituição Federal).

Sendo todos iguais e, da mesma forma, sendo a saúde um direito de todos, não há o que questionar quanto à divisão de responsabilidades para o fornecimento dos recursos adequados para o resguardo da saúde. Não há uma divisão, visto que, todas as normas que asseguram esse direito deixam claro que compete ao Poder Público o fornecimento, o qual abrange Estado, Município e União. Desta forma, não se justifica ficar gastando tempo discutindo de quem será a responsabilidade, pois essa dúvida já esta saciada da forma mais simples, basta interpretar as normas jurídicas, Poder Público, o qual engloba as três esferas.

Consequentemente, deve-se pensar que, enquanto se discute a responsabilidade quanto ao fornecimento, pessoas carentes, enfermas e na maioria das vezes caquéticas, se encontram à espera de seu tratamento, enquanto os órgãos públicos ainda discutem uma questão que já se encontra resolvida, visto que a responsabilidade não é individual e sim solidária de todos os membros.

Portanto, conclui-se que assegurando o estabelecido na Constituição Federal, em seu artigo 196, em consonância com o artigo $5^{\circ}$, caput, da mesma Carta, juntamente com o explícito em demais leis complementares, os Poderes Públicos têm a obrigação solidária de fornecer os recursos adequados para o resguardo da vida do ser humano, 
independentemente de atuais listas que fazem uma divisão quanto ao fornecimento. Da mesma forma, deve-se pensar que, enquanto se discute, muitos estados de saúde vêm a agravar-se e muitas contas nas farmácias vêm a aumentar tal necessidade exclusivamente com um objetivo, assegurar a saúde que se encontra debilitada por mais um lapso de tempo, enquanto o Poder Público gasta seu tempo discutindo quanto a real necessidade e responsabilidade.

\section{BIBLIOGRAFIA}

BRASIL, Constituição da República Federativa do Brasil de 1988

BRASIL, Lei $\mathrm{n}^{\circ} 10.741$, de $1^{\circ}$ de outubro de 2003, dispõe sobre o Estatuto do Idoso e dá outras providências.

BRASIL, Lei n ${ }^{\circ} 8.069$, de 13 de julho de 1990, dispõe sobre o Estatuto da Criança e do Adolescente e dá outras providências.

LENZA, Pedro. Direito Constitucional Esquematizado. 13º ed. São Paulo: Saraiva, 2009

MENDES, Gilmar Ferreira; Coelho, Inocêncio Mártires; Branco, Paulo Gustavo Gonet. Curso de Direito Constitucional. $3^{\circ}$ ed. São Paulo: Saraiva, 2008

MORAES, Alexandre de. Direito Constitucional. 15ºd. São Paulo: Atlas, 2004

On line, http// www.Saude.gov.br, 12/03/2011

On line, http// www.tjjus.gov.br, 29/01/2011 